\title{
Open windrow composting of polymers: an investigation into the rate of degradation of polyethylene
}

\author{
Georgina Davis, Adam Read, Hugh Bulson, David Harrison and Eric Billett \\ Design Department, Brunel University, Runnymede, Surrey TW20 0JZ, UK \\ The Organic Resource Agency, MHSP, Malvern WR14 3SZ, UK \\ Environmental Resources Management, Wallbrook Court, Oxford OX2 0QS, UK
}

\begin{abstract}
The compostability of degradable polymers under open windrow composting conditions is explored within this paper. Areas for consideration were the use of, and impacts of, degradable polyethylene (PE) sacks on the composting process and the quality of the finished compost product. These factors were investigated through polymer weight loss over the composting process, the amount of polymer residue and chemical contaminants in the finished compost product, the windrow temperature profiles and a bioassay to establish plant growth and germination levels using the final compost product. This trial also included a comparative study of the weight loss under composting conditions of two different types of 'degradable' polymer sacks currently on the European market: PE and a starch based product. Statistical analysis of the windrow temperature profiles has led to the development of a model, which can help to predict the expected trends in the temperature profiles of open compost windrows where the organic waste is kerbside collected using a degradable PE sack.
\end{abstract}

Author Keywords: Author Keywords: Open windrow composting; Degradable; Polyethylene; Starch; Waste collection

\section{Introduction}

The number of separate kerbside organic waste collection systems operated by UK Local Authorities (LAs) has risen sharply as a result of the implementation of the European Landfill Directive (99/31/EC) (European Commission, 1999) into UK legislation on the 16th July 2001. The Landfill Directives seeks to reduce the amount of biodegradable municipal waste (BMW) 
going to landfill in three successive stages, eventually to $35 \%$ of the 1995 total of BMW by 2020 , because of the negative environmental impacts associated with leachate and methane production ( Hudgins, 1999). The Department for the Environment, Transport and the Region's ( DETR, 2000) Waste Strategy 2000 (England and Wales), set targets for Waste Disposal Authorities to reduce the amount of BMW sent to landfill by introducing a tradable permit system designed so that the UK could meet EU Landfill Directive targets ( $\underline{\text { Read, } 1999}$ and Read, 2000). These targets have resulted in the proliferation of kerbside collection systems which have targeted BMW, and many LAs are currently conducting pilot trials, research projects and system reviews to determine the best possible way of segregating, collecting, transporting and processing this specific waste stream

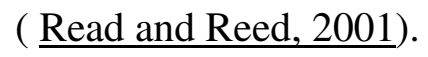

Waste auditing data obtained by the Organic Resource Agency (ORA) indicates that up to half of the total composition of household generated waste in the UK is organic garden and kitchen waste, and is thus part of the BMW category (Davis, 2001). Thus, an effective strategy for kerbside collection of the source segregated BMW component from the residual municipal waste could lead to the production of a high quality compost product and reduce the amount BMW going to landfill ( Read and Reed, 2001). Many UK LA's have also seen the potential of targeting the organic waste stream as a way of attaining their recycling targets (

Polymer sacks, currently marketed in the UK for garden sweeping wastes and the kerbside collection of organic wastes can be broadly categorised into degradable and biodegradable types. Guillet (1995), defined biodegradable polymers as being capable of being chemically transformed by the action of biological enzymes or micro-organisms into products which themselves are capable of further biodegradation. Whilst Stevens (2002), defined a degradable polymer as capable of undergoing a significant change in its chemical structure under specific environmental conditions. Stevens (2002), also goes on to state that a compostable polymer will undergo 'biological degradation during composting to give carbon dioxide, water, inorganic compounds and biomass at a rate that is consistent with other compostable materials, leaving no distinguishable or toxic residues'.

The work reported within this paper is based on a 2-year pilot study to assess the suitability of using polymer sacks for the kerbside collection and composting of selected BMW (uncooked fruit, vegetable kitchen waste and garden wastes only) from households. The pilot project that commenced in 2001 and was based in Suffolk Coastal District Council, the purpose of which was to identify an effective method of increasing the district recycling rate to $24 \%$ by $2003 / 04$ and $36 \%$ 
in 2005/06 (DETR, 2001). Monitoring of the composting process and the resulting compost products are essential to determine whether the polyethylene (PE) sacks used are compostable, and whether they have a detrimental effect on either the composting process or the compost product.

\section{The degradation process}

Biodegradable polymers can be broadly divided into three categories based on the origin of the raw materials and the processes used in their manufacture (Nayak, 1999):

- Natural biodegradable polymers;

- Synthetic biodegradable polymers;

- Modified natural biodegradable polymers.

Many polymers have been purposely designed to resist degradation. The challenge is to now design polymers that have the 'necessary functionality' (Narayan, 2000) during use, before degrading fully under specified environmental conditions.

Substantial work on the degradation of PE has been conducted in Sweden by Albertsson (1989). This research concluded that the degradation of PE occurs at a rate of approximately $0.5 \%$ of weight per annum. The degradation of PE is primarily initiated by irradiation from a UV source and impacted by other factors such as molecular weight, additives and surface area ( Kawai et al., 1999). Micro-organism attack on PE is a secondary process ( $\underline{\text { Scott, 1975). }}$.

The presence of PE in composts in some European countries such as Germany, is prohibited, as PE is unable to pass their standards governing compostability. Germany's standard DIN V 54900 which tests the compostability of polymeric materials, (German Standard Agency, 1997) which is in line with the corresponding European Standard (CENTC 261 standard EN 13432, 1999), defines methods for testing the compostability of a polymeric material. The test indicates whether a polymer will degrade and be converted into constituents of the compost under controlled conditions.

This standard determines if the composting process or quality of the final product is effected by the polymer or its degradation products.

The word degradation implies a loss of properties. The trigger for degradation could be a 'microbially, hydrolytically or oxidatively susceptible linkage built into the backbone of the 
polymer' or alternatively 'additives that catalyse breakdown of the polymer chains' (Narayan, 2000). This 'trigger' can be specifically designed to ensure degradation does not occur within the 'in-use lifetime' (i.e. during filling and transport by the householder) but will begin upon disposal within a given environment. Degradation will ultimately depend on several factors such as the microbial activity of the disposal or treatment environment. Within a composting environment, thermo-oxidation plays the dominant role in degradation, since temperatures can easily exceed 60$70{ }^{\circ} \mathrm{C}$ for a prolonged period of time, even during the UK's colder months.

Polymers can degrade in a variety of ways through interacting with:

- Sunlight (photo-oxidation);

- Bacteria (micro-organisms);

- Chemicals;

- Macro-organisms (invertebrates and insects);

Wool (1995) suggests that degradable polymers can be made more susceptible to macro-organism attack by incorporating 'feeding stimulants' (i.e. starch which is a natural food source for insects possessing specific amylase digestive enzymes).

Biodegradable plastics are attacked and degraded by enzymes from naturally occurring microorganisms (such as bacteria and fungi) encountered under specific conditions found in soils and composts. The micro-organisms digest small fragments of the macro-molecules. The end products of this metabolic process are then excreted and become part of the natural cycles of materials. Micro-organisms need food (nutrients); thus the rate of nutrients available also has a direct influence on the rate of degradation. Moisture is also an important factor affecting microbial activity in composting and ultimately the rate of degradation. Too much moisture will create anaerobic conditions, whilst if too dry, the microbes will dehydrate (Read et al., 2001).

\section{Degradable polymer sacks for the kerbside collection of organic wastes}

Polymer sacks have been used by UK Local Authorities, to help facilitate the hygienic and sanitary collection of organic wastes from households. Such sacks can help control the release of odours and can limit insect infestation during the storage, collection and transport stages. They can also reduce the need to wash collection receptacles (bins or boxes) by acting as a liner and if properly sealed, control the release of liquids from the waste during the transportation phase. 
This can effect the type of vehicle used for the collection, the frequency of the collection and reduce the contamination of other recyclables within the domestic refuse stream.

Polymer sacks have great potential for the kerbside collection of organic wastes because:

- Sacks can be produced as transparent, allowing collection operatives to easily ascertain any contamination;

- Sacks can be produced in a wide variety of different sizes to correspond with different capacity requirements;

- Sacks do not require any changes to collection vehicles, unlike the addition of bin lifting equipment where the residual waste is collected using a wheeled bin;

- Sacks are easier to store for householders;

- Sacks are not as visually intrusive as containers and wheeled bins.

\section{Trial conditions}

A trial was conducted using two designated collection rounds with a similar housing stock and population, where organic wastes had not previously been collected. The two rounds were chosen as they had distinct collection rounds that corresponded to the 'new' kerbside collection rounds for BMW. Auditable data relating to the tonnages of residual waste collected was also available.

Access to historic waste data is essential to establish the success of any recycling initiative as it provides a base line of tonnage collected taking into account seasonal fluctuations.

In the first BMW collection area, the trial comprised of approximately 2500 households, which were provided with degradable PE sacks, for source separating their selected organic wastes. These degradable PE sacks were then collected from the kerbside under a separate fortnightly collection scheme, which did not affect their regular domestic waste collection system. This waste (the organic element) was then taken to a composting facility where it was stored, shredded and open windrow composted. Throughout the collection and composting process the organic 'feedstock' was kept distinct from other waste streams so that the compost process and quality of the final product could be carefully monitored.

The second area was used as a control. A further 1600 households were separating the same specified organic wastes using a 1401 wheeled bin. The waste was then collected and treated using the same methodology as for the degradable PE sacks, ensuring that results were not affected by 
processing but were representative of the differences in collection container material. The organic waste feedstocks were collected during the same week, using the same collection frequency, with the shredding and composting processes being undertaken at the same time for both streams.

\section{Methodology}

\subsection{Polymer weight loss}

Visual analysis of the open windrows containing the shredded PE sacks indicated that the PE was not degrading at the same rate as the organic matter, resulting in a finished compost with a highly visible proportion of PE. In order to establish the rate of PE degradation within the open windrows, a polymer weight loss methodology was devised. To put the results of the PE into context, the methodology was also applied to a starch based sack. Measuring weight loss in a polymer sample is a cheap and easy way to establish a rate of degradation. However, the interpretation of the results is not simple. For polymers that have been 'incubated' for a period of time there may actually be a weight gain as a result of micro-organisms colonising the polymer. Kawai et al. (1999) suggested that degradation is initiated at the surface of a polymer, thus weight loss is proportional to the surface area, and is thus calculated as weight loss per surface area.

To assess polymer surface weight loss, over a controlled period, pre-weighed polymer samples were secured in mesh bags (Davis et al., 2002). A series of these samples were then buried $1 \mathrm{~m}$ into an open windrow of the collected composting organic waste (each windrow typically measuring 2-3 m high, 3-4 m in width and up to $10 \mathrm{~m}$ long depending on volume of green waste to be composted). Individual samples were then removed periodically, and re-weighed to establish weight loss and visual degradation over time. The polymer samples within the mesh bags had been cut from 'compostable' sacks (obtained from companies currently supplying sacks to a number of UK Authorities), into a single ply sheet of approximately 200 by $300 \mathrm{~mm}$ and then weighed before being contained within one of the mesh bags.

It was essential to ensure that the degradation process ceases upon removal from the test environment so that the results were not invalidated should there be a delay before analysis. To ensure degradation ceases, it was necessary to carefully brush and/or wash the degradable polymer sample, then carefully dry it before analysis in order to remove any detritus. 
Some biodegradable polymers are sensitive to moisture, particularly those from starch sources (starch is hydrophilic). Due to the low initial weights of the samples residual detritus or moisture could impose a significant degree of error.

\subsection{Polymer residues in final compost product}

It is usually necessary to screen the finished product after the composting process is complete, before marketing or delivery to the consumer. The size at which a compost product is screened is dependant on the final end-use of the product. For example, an agricultural application may require a product that has been screened at $20 \mathrm{~mm}$, whilst for a horticultural application the consumer will expect a high quality product possibly screened at $8 \mathrm{~mm}$.

From green waste compost, oversized items were rejected and this usually comprises wood and coarse materials because the 12-week composting process is not sufficient to break down the substances such as lignin and cellulose.

It was essential that the composition of the rejects could be determined for the control windrow (material colleted in bins) and the windrow containing the PE. Representative samples were taken of each of the finished composts, prior to commercial screening, and hand screened using a $12 \mathrm{~mm}$ screen.

\subsection{Windrow temperature profiles}

Monitoring of composting temperatures provides a site operator with an indication of the progress and success of the composting process. More emphasis is being placed on the importance of obtaining specified temperatures for given durations to fulfil industry standards, and to reassure end users that the final compost product is of the expected quality in terms of pathogen kill and weed seed elimination, both of which can be controlled if the required time-temperature profile is achieved. The Composting Association has produced guidelines, (which are encompassed by The British Standards Institute's Specification for Composted Materials, BSI PAS 100), that stipulate compost windrows should be maintained at $55^{\circ} \mathrm{C}$ for a total of 14 days in order for the compost to be sanitised. 
Daily monitoring of the temperature of the two windrows was undertaken in order to establish the individual temperature profiles of the control windrow and the windrow containing the shredded degradable PE sacks.

During the 2-year trial, a total of four sets of temperature profiles were obtained. Care was taken to ensure that every set of windrows was treated in exactly the same way; for example, the organic waste was collected, shredded, formed into windrows on the same days and mechanically turned at the same intervals.

The windrows, although kept separate throughout the composting process, were situated on the same site and subject to the same climatic factors, thus ensuring comparability.

\subsection{Chemical analysis}

Chemical analysis of the degradable PE sacks was undertaken as a precautionary measure to ensure that there were no potential contaminants within the polymer that could affect the quality or safety of the final compost product.

The chemical analysis of composts is a frequently used method for establishing the quality of a compost (de Bertoldi et al., 1983 and de Bertoldi, 1999). The chemical analysis includes parameters related to the progress of the composting process and suitability for final use, such as carbon to nitrogen ratio $(\mathrm{C}: \mathrm{N}), \mathrm{pH}$, electrical conductivity and levels of heavy metal contamination.

The PE sacks contained metals that would not be routinely tested for in a standard compost chemical analysis, these metals were incorporated into the chemical analysis of the compost. Heavy metal analysis did not indicate that the constituent metals within the PE sacks were contributing to a significant increase in the levels of metals detected within the final compost

product matrix. This was due to the small amounts of these metals present in the PE mix and the high dilution factor with organic waste.

\subsection{Bioassay}

A bioassay is a method to assess the contamination by weed propagules such as roots and stems (which could lead to weed propagation) and phytotoxic substances through a plant growth test (The Composting Association, 2000). 
A full bioassay of the finished compost containing the degraded starch liners was undertaken in accordance with the UK's Composting Association Standards for Composts Test Method (2000). The bioassay consisted of a pot based trial conducted under controlled green house conditions for a 6 week period.

With a view to assessing levels of phytotoxicitiy and weed contamination, the Composting Association's standards for composts stipulate that compost will be acceptable if, after following their method, the compost produced bioassay results are no more than $20 \%$ lower than the control. Tomato seeds (variety-Money Maker) were sown into the compost and germination, vigour, phytotoxicity score and fresh weights were recorded and compared against a control treatment containing only peat amended with fertiliser.

\section{Results}

\subsection{Polymer weight loss}

Fig. 1 shows the percentage surface weight loss results obtained for two different degradable polymer samples on the UK market.

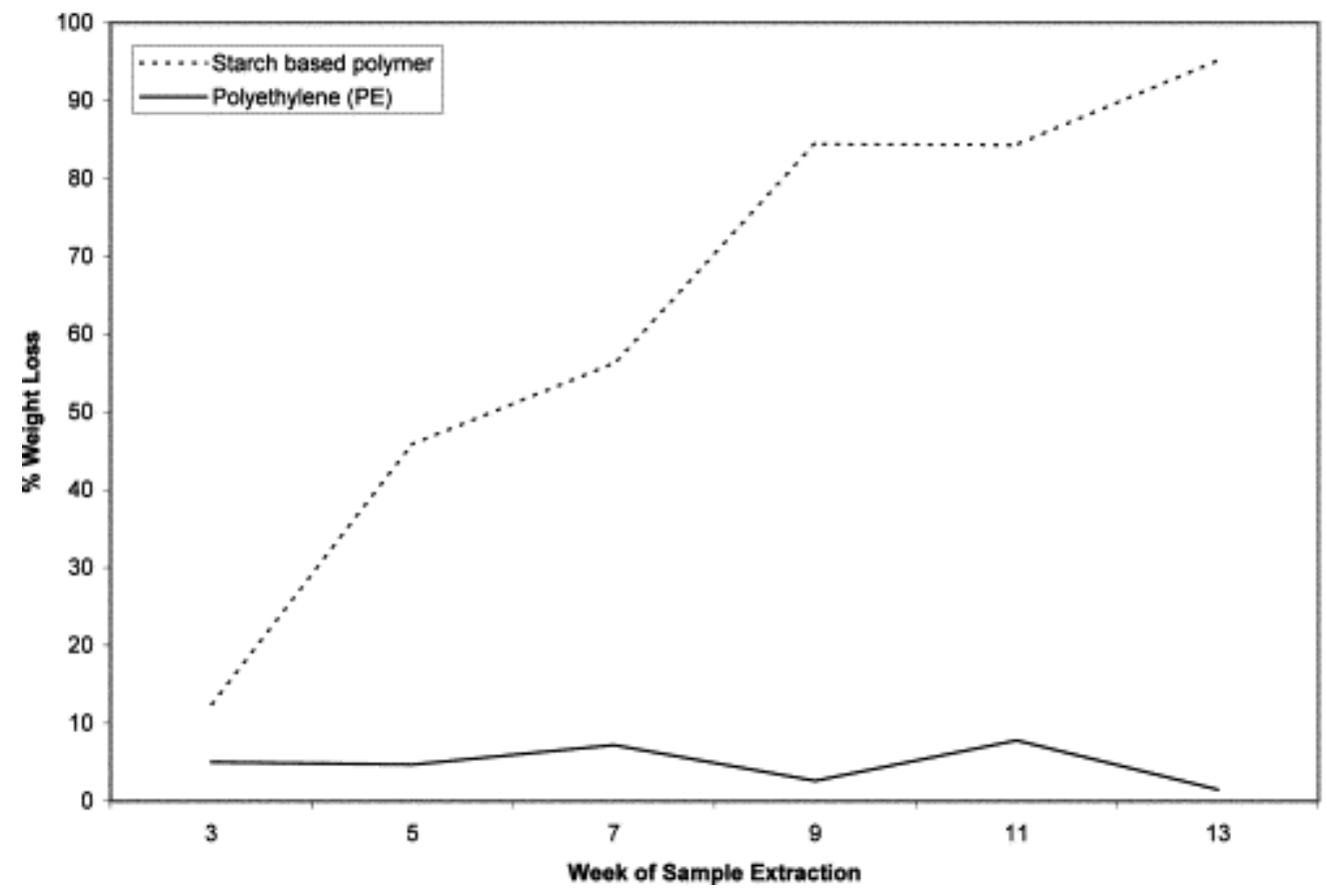

Fig. 1. Percentage polymer weight loss over time-comparison of starch and PE. 
The weight losses in Fig. 1 were calculated as percentage surface weight loss values and statistically analysed using the Wilcoxon matched pairs design, with the resulting probability of 0.028 which is significant at the $5 \%$ level. Thus, the percentage weight loss experienced by the starch product over 15 weeks is significantly greater than the percentage weight loss experienced by the PE product. No 'visible' degradation had occurred to the PE samples and the weight loss data was inconclusive.

\subsection{Polymer residues in final compost product}

$\underline{\text { Table } 1}$, shows the relative percentage weights of the rejects from the various samples.

Table 1. Sample and rejects weights and percentage rejects for the screening process (BSI PAS 100)

\begin{tabular}{lcccc}
\hline Designation & Weight of sample/kg & Weight of rejects/kg & \% rejects to compost & wejets that are PE \\
\hline Windrow 1-control & 41.4 & 7.9 & 19.3 & 0.42 \\
Windrow 1-bag & 42.8 & 11.3 & 26.5 & \\
Windrow 2-control & 36.4 & 3.6 & 9.9 & 0.31 \\
Windrow 2-bag & 37.6 & 8.8 & 23.4 & 0.39 \\
Windrow 3-control & 41.6 & 3.2 & 7.7 & 17.1 \\
Windrow 3-bag & 31.6 & 5.4 & 17.5 & 0.34 \\
Windrew 4-control & 45.0 & 7.9 & 23.3 & \\
Windrow 4-bag & 34.7 & 8.1 & & \\
\hline
\end{tabular}

The volume of rejects also relates to the type of green waste shredder used to shred the organic waste prior to windrow formation. This can make it difficult to compare the volumes of rejects between the different windrow sets. However, both the control and PE sack collected organic wastes were shredded on the same day using the same shredder, thus a direct comparison can be made between the windrows within the same set.

The total percentage of rejects within the control windrows were continuously lower than those found in the windrow containing the PE. However, the total weight of PE was very small (although of high volume and therefore highly visible). If the feedstocks were similar, and the shredding process and compost treatments had been identical, there had to be another reason for the larger amount of rejects in the windrows containing the PE. Therefore, analysis of the data recording the windrow temperature profiles was undertaken. 


\subsection{Windrow temperature profiles}

The temperature profiles of the windrows when plotted against time, indicated graphically that the temperatures experienced within the windrows containing the shredded PE reached a lower average temperature than the control windrows that did not contain any PE. In all cases the average temperature in the control windrows was higher than that experienced in the windrow containing the PE (Fig. 2).

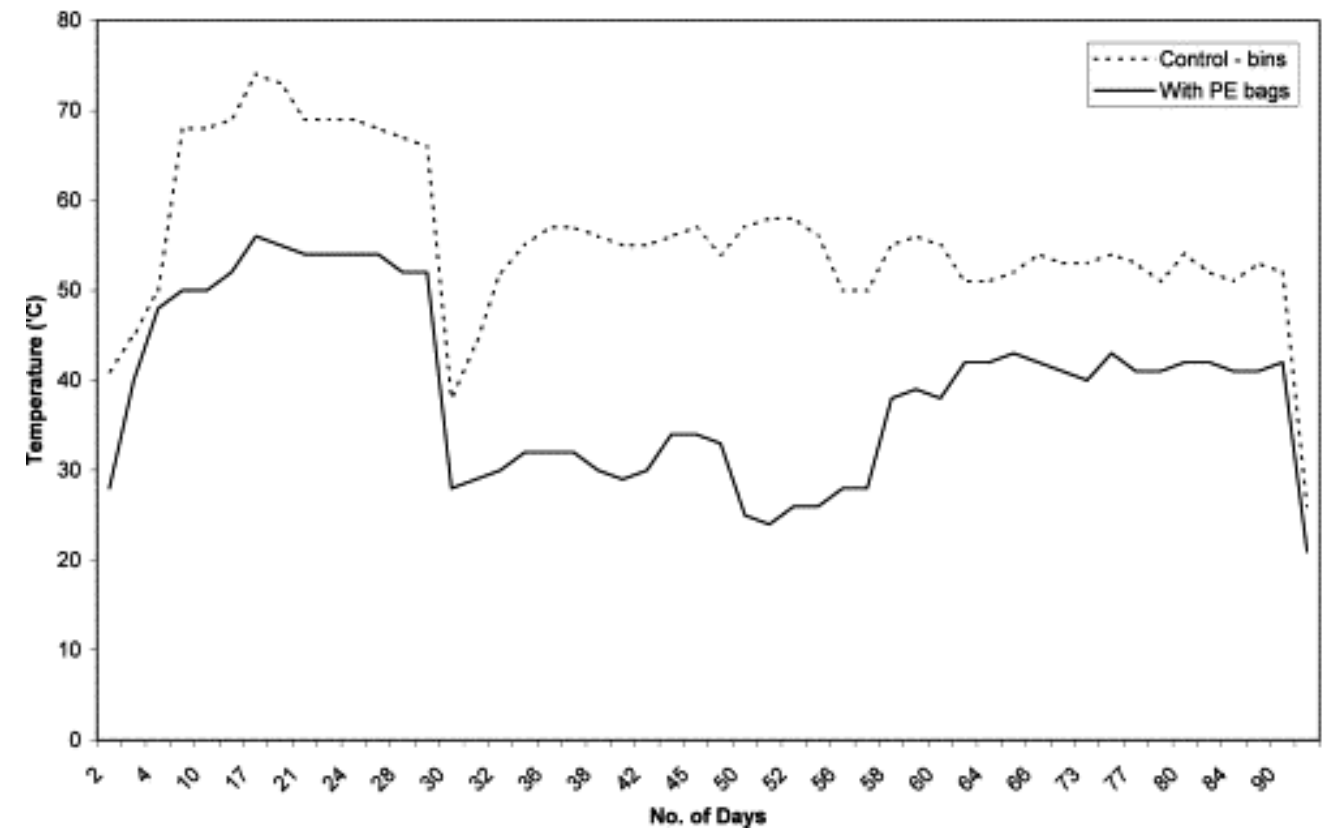

Fig. 2. Windrow temperature profile for set [3]— control versus PE containing windrow.

Scatter diagrams of the four sets of windrow temperature profiles proved insufficient to determine if a significant linear relationship existed between the temperatures recorded in the control windrow and those recorded in the windrow containing the PE. Correlation analysis was therefore used to determine the strength of the relationship between the temperatures over time. Correlation analysis is a measure of the degree of association between two variables. The following correlation coefficients for the four sets of windrows were determined:

Windrows [1] -0.672

Windrows [2]-0.929

Windrows [3]-0.686

Windrows [4]-0.668 
The correlation coefficients for the four windrows show that there was a relationship between the temperatures recorded in the control windrows and the windrows containing the shredded degradable PE.

Regression modelling analysis was then applied to the data using the statistical package, GENSTAT 6. Regression analysis is the process of constructing a mathematical formula that can be used for predicting the value of one variable on the basis of one known value of another variable. In this case a formula for predicting the open windrow temperatures when a shredded degradable PE is introduced into the organic compost feedstock.

Analysis of variance was used to choose the simplest model that adequately described the observed relationship. A straight-line relationship between the temperatures recorded in the control windrows and the windrows containing the PE was determined. This relationship is the same for all windrows, that is, the slope of the four regressions lines is the same. The $R$-squared value was $66.4 \%$, which indicates that two-thirds of the observed variability in the relationship between the control windrows temperature and the PE containing windrows has been explained.

The following four equations were determined for each of the four sets of windrows:

$$
\mathrm{CWT}_{\mathrm{emp}}=27^{\circ}+0.6^{\circ} \mathrm{PEWT}_{\mathrm{emp}}
$$

$$
\mathrm{CWT}_{\mathrm{emp}}=25^{\circ}+0.6^{\circ} \mathrm{PEWT}_{\mathrm{emp}}
$$

$$
\mathrm{CWT}_{\mathrm{emp}}=33^{\circ}+0.6^{\circ} \mathrm{PEWT}_{\mathrm{emp}}
$$

$$
\mathrm{CWT}_{\mathrm{emp}}=27^{\circ}+0.6^{\circ} \mathrm{PEWT}_{\mathrm{emp}}
$$

where: $\mathrm{CWT}_{\mathrm{emp}}$, the temperature of the control windrow; $\mathrm{PEWT}_{\mathrm{emp}}$, the temperature of the windrow containing the shredded degradable PE. All temperatures shown are in degrees Celsius $\left({ }^{\circ} \mathrm{C}\right)$. 
The four regression equations show that the initial compost starting temperatures within the control windrows were higher $\left(25-33^{\circ} \mathrm{C}\right)$ than the initial temperatures within the windrows containing the PE. The equations also indicate that the rate of temperature increase within the windrows containing the PE was significantly higher than in the control windrow. For every $1{ }^{\circ} \mathrm{C}$ increase in temperature in the PE containing windrow, the control windrow only increased by $0.6^{\circ} \mathrm{C}$.

\subsection{Chemical analysis}

Analysis of the PE sacks established that metals from the first transition series were incorporated into the polymer matrix. Transition metals are used to weaken the carbon-carbon backbone of a polymer, making it more degradable. Such metals occur naturally in some soils and were in small amounts within the PE bags ( $\underline{\text { Table } 2)}$.

Table 2. Chemical analysis of degradable PE sacks

\begin{tabular}{lll}
\hline Deteminand & Average bag value & Units \\
\hline Copper in solution & 35 & $\mathrm{mg} / \mathrm{kg}$ \\
Cobalt in solution & 35 & $\mathrm{mg} / \mathrm{kg}$ \\
Other elements & None at significant levels & \\
\hline
\end{tabular}

Chemical analysis of the compost has shown that the $\mathrm{C}: \mathrm{N}$ ratio of the windrows containing the PE are higher than the $\mathrm{C}: \mathrm{N}$ ratio for the control windrows containing no PE. A low $\mathrm{C}: \mathrm{N}$ ratio is desirable as it shows that the soluble carbon is being degraded and released as carbon dioxide, thus causing a decrease in carbon relative to nitrogen, decreasing the $\mathrm{C}: \mathrm{N}$ ratio. One explanation for this, is the period of confinement of the organic waste within the sealed PE bags prior to shredding.

\subsection{Bioassay}

$\underline{\text { Table } 3}$ shows all of the parameters specified within the Composting Association Standards and the relative scores for the PE containing compost and the control compost product. All parameters were met, with the exception of total fresh weights. 
Table 3. Results of phytotoxicity and weed contamination bioassay for the finished compostscontrol windrow (feedstock sources via wheeled bins) and PE sack sources green waste

\begin{tabular}{|c|c|c|}
\hline Analysis & Control windrow & Windrow containing PE \\
\hline $\begin{array}{l}\text { No, of weeds/line of sam- } \\
\text { ple }\end{array}$ & 0 & 0 \\
\hline $\begin{array}{l}\text { Dilution ration of } \\
\text { compostpeat }{ }^{3}\end{array}$ & $1: 2$ & $1: 1.3$ \\
\hline Gemination & & \\
\hline $\begin{array}{l}\text { After } 14 \text { days } \\
\text { After } 28 \text { days } \\
\text { Vigor score }\end{array}$ & $\begin{array}{l}95 \% \\
95 \%\end{array}$ & $\begin{array}{l}95 \% \\
100 \%\end{array}$ \\
\hline After 14 days & 4.5 & 4.25 \\
\hline After 28 days & 3.75 & 3.75 \\
\hline Phytotoxicity scored & 0 & 0 \\
\hline $\begin{array}{l}\text { Total fresh weight per } \\
\text { planfe }\end{array}$ & $51 \%$ & $50 \%$ \\
\hline
\end{tabular}

When comparing the fresh mass of seedling per sample of compost compared with the average of the control, all the composts faired below the target level ( $80 \%$ of that of the control). Reduced seedling weight can be caused by low levels of phytotoxicity present in immature compost, high soluble salt levels or ammonia production which can damage young roots.

The results from the bioassay indicate that the composting process had been effective at eradicating all weed seed contamination in all samples. No visible sign of compost phytotoxicity were recorded in any of the samples. The bioassay also indicates that the presence of the shredded degradable PE and its degradation products within the final compost product did not inhibit plant growth or seed germination. However, a bioassay cannot predict long-term or accumulative effects of repeated application of composts containing degradable PE on plant growth.

Despite there being no negative effects on plant growth due to the presence of the un-degraded PE the perception of the purchasers of the final compost product is that it is inferior to composts that do not have any visual contamination, and this clearly has a detrimental impact on potential end markets for this type of compost.

\section{Discussion of practicality of using degradable polymers for the kerbside collection of BMW}

Degradable sacks have additional complications over more traditional receptacles such as bins and boxes. For example, composting facilities in the UK and throughout Europe are usually prohibited 
from accepting any plastics on site. Of the pilot schemes currently using degradable sacks in the UK, many are operating under an exemption obtained from the Environment Agency. On-going collections using degradable sacks may require changes to site licenses that can be time consuming to obtain.

The dry matter content undertaken as part of the chemical analysis has indicated that the windrows containing the PE typically have a lower proportion of dry matter than the control windrows. This is in line with the observation that the windrows containing the PE are typically wetter and thus harder to move and screen than the control windrows. Further analysis is being undertaken to determine if the poor material structure of the windrow is as a result of the content of the PE.

The sacks also have an on-going purchase and distribution cost due to their limited shelf-life, in addition to increasing processing costs at the compost site. As a result, many authorities that have trialed degradable sacks are changing to wheeled bins. The Authority where this trial was conducted has decided to dispense with PE sacks and expand the kerbside collection of organic wastes using 1401 wheeled bins.

It is essential that the waste collection authority and treatment/disposal facility are consulted and included in the discussion on deciding which collection strategy/method to collect organic wastes. Councils need to discuss collection systems with compost processors early in this planning stage. The reasons for this are twofold, firstly site licenses can take over 12 months to obtain and second it is essential that the composting facility can deal with the quality of the organic waste being presented and that the volume of waste is within their license conditions. The type of collection strategy implemented (frequency of collection and type of collection vessel) will have a significant affect on the volume of waste collected. A further study detailing the differences in participation rates and the volumes of waste collected in this scheme is currently being finalised.

The PE windrow did not achieve the same elevated temperatures as those experienced within the control windrows. This is of significance because it is the higher temperatures over extended periods that effectively kills pathogens and weed seeds (the sanitisation process) that ultimately determines the quality and safety of the final compost product. Compost windrows that do not reach the desired temperatures for sanitisation should be blended with fresh feedstock and recomposted until sanitisation has been achieved or, alternatively, can be used for landfill day cover, although The British Standards Institution's Specification for Composted Materials, (2002) BSI PAS 100 does not categorically state that the compost should be disposed of. This can cause 
logistical problems for the site operator who must invest more man-hours and space to re-compost the organic waste and with any disposal of the compost incurring landfill costs, in addition to the Local Authority losing its right to claim the tradable permits for the weight of organic waste collected.

Further windrow temperature profiles of the PE containing and control windrows would have helped to increase the observed variability in the relationship between the control windrows and the PE containing windrows. Unfortunately in this particular case, the composting operator was becoming increasingly frustrated at the extra processing and costs that the PE sacks required. This resulted in the PE sacks being left for increasing periods of time prior to shredding, to reduce inconvenience and financial cost (hire of a green waste shredder and man-hours). Increasing the period of containment of the organic waste within sealed PE sacks promotes anaerobic conditions, which then inhibits any subsequent aerobic composting process, so it is therefore essential that any waste collected in degradable sacks is shredded as soon as possible.

The aim of this research was to establish if degradable PE sacks were suitable for the kerbside collection of organic wastes and their subsequent composting using open windrow techniques. Research undertaken during this pilot scheme has demonstrated that although PE sacks are suitable for the collection of organic wastes, they are not compostable under open windrow conditions. According to Stevens (2002), the determining features of a compostable polymer was its ability to undergo biological degradation at a rate consistent with other known compostable materials, in addition to leaving no visually distinguishable residues within the final compost product. Polymer weight loss analysis indicated that the PE exhibited a small amount of degradation over the composting duration.

The rate of degradation of the PE did not match the rate of degradation observed within the organic waste, where an expected volume reduction is between 40 and 60\%, resulting in an actual increase in the amount of PE to organic matter over the composting period and ensuring that the PE within the windrows became increasingly visually intrusive. This can be a point of concern for regulatory bodies, such as the Environment Agency in the UK who are concerned about its potential for littering.

The starch based degradable polymer did completely degrade within the open windrow composting process, leaving no visible residue in the final compost product. If a determining feature of the marketability of a final compost is its visible appearance, then PE which fragments 
into highly visible residues that are difficult to remove through screening, is at a disadvantage to the alternative 'starch based' products, which quickly discolour and degrade into small fragments that become indistinguishable within the compost matrix in a few weeks.

However, despite their success in degrading effectively under composting conditions, there is concern from the end consumers regarding the origin of the starch and the lack of guarantees that the starch is GM free. So starch based polymers do not necessarily offer a better alternative for the collection of kerbside BMW from households, particularly if the desired final compost market is the organic sector.

\section{Conclusions}

In order for a degradable sack to be successful for kerbside collection and subsequent composting of organic wastes, it must provide problem-free processing at the compost plant in addition to providing convenience and a reasonable service life to the householder.

Although PE sacks are convenient to the householder and provide a stable and strong receptacle for the kerbside collection of organic wastes, the PE sacks require additional processing at the composting facility, by way of shredding to break open the bags and assist with mechanical polymer degradation as well as increased screening processes to remove as much of the visible PE before marketing. Rejects from the screening process comprise of the woodier organic wastes as the carbon tends to be less soluble where it is protected with lignin. These woodier wastes are blended into the 'fresh' compost matter to add structure to windrows and in time will break down sufficiently to clear the screening process. However, the high volume of PE in the screened rejects has resulted in the rejects being landfilled. The increased processing requirement and the landfill of

rejects has both a resource consumption and financial implication, essentially increasing the cost of producing what is perceived by the end consumer as an inferior compost product.

\section{References}

Albertsson, A., 1989. The degradation of polyethylene. Applied Polymer Science 25 12, p. 1655. Davis G. Waste auditing and what it can do for you. Waste Management, Institute of Wastes Management, Northampton, UK, September 2001. pp. 37-9.

Davis, G. et al., 2002. In: The Performance of Degradable Polymers within Wastes Management. Waste Management and the Environment, WIT Press, pp. 287-296. 
de Bertoldi, M., Vallini, G. and Pera, A., 1983. The biology of composting: a review. Waste Management and Research 1, pp. 157-176.

de Bertoldi, M., 1999. The control of the process and compost quality. In: Bidlingmaier, W., de Bertoldi, M., Diaz, L and Papaddimitriou, F.K., Editors, 1999. Organic Recovery and Biological Treatment, Rhombos-Verl, Berlin, pp. 47-53 September .

DETR. Waste Strategy: A Waste Strategy for England and Wales. Department for the Environment, Transport and the Regions, HMSO, London, 2000.

DETR. Guidance on Municipal Waste Management Strategies. Department for the Environment, Transport and the Regions: London, March 2001.

DIN 54'900. Prufung der Kompostierbakeit von Kunststoffen (Testing of the Compostability of

Polymeric Materials). Parts 1, 2, 3 and 4. German Standards Agency, 1997.

EN 13432. Requirements for Packaging Recoverable through Composting and BiodegradationTest Scheme and Evaluation Criteria for the final acceptance of packaging. European Committee for Standardisation. Brussels, 1999.

European Commission. Council directive 1999/31/EC on the landfill of waste. Official Journal of the European Communities 1182/1-19, 16 July, 1999.

Guillet, J., 1995. In: Plastics and the Environment. Degradable Polymers: Principles and Applications, Chapman and Hall, London, pp. 217-246.

Hudgins M. Aerobic landfill studies from the USA. Paper presented at the 1st international conference on solid waste, Rome, April 1999.

Kawai F. et al. Biodegradability of photodegradable polyethylene and polyethylene wax by microorganisms. 5th International Scientific Workshop on Biodegradable Plastics and Polymers. Macromolecular Symposia. Stockholm, Sweden, 9-13th June 1998. Macromol Symp. 1999;144:73-84.

Nayak, P., 1999. Biodegradable polymers: opportunities and challenges. Journal of Macromolecular Science: Part C-Reviews in Macromolecular Chemistry and Physics C39 3, pp. 481-505.

Narayan R. Starch based biodegradable plastics and products. Natural polymers and composites. Conference proceedings, Sao Pedro, Brazil. May 2000, pp. 201-205.

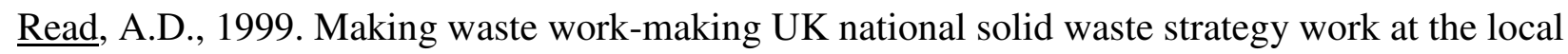
scale. Resources Conservation and Recycling 26, pp. 259-285.

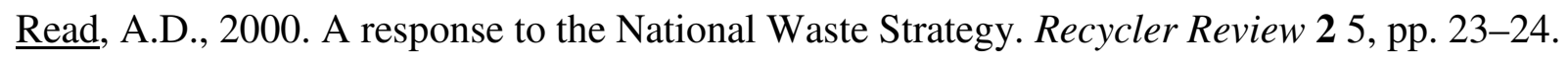
$\underline{\text { Read AD. Daventry's High Diversion Recycling Programme-how to engage (and challenge) the }}$ public, recycle and compost domestic waste, and meet Government targets ahead of schedule, 
presented at 18th International Congress on Solid Waste Technology \& Management, Philadelphia, March 2003.

Read, A.D., Hudgins, M. and Phillips, P.S., 2001. Aerobic test cells and their implications for sustainable waste disposal. The Geographical Journal 167 3, pp. 235-247.

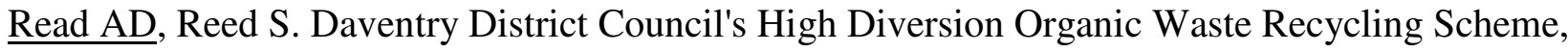
presented at the Waste in the 21 st Century Conference, University College Northampton, Northampton, UK, January 2001.

Scott, G., 1975. Polymer Age 6, p. 54.

Stevens, E.S., 2002. Green Plastics: An Introduction to the New Science of Biodegradable Plastics, Princeton University Press.

The British Standards Institution's Specification for Composted Materials, November 2002.

Standards for Composts Test Method. The Composting Association. CATM/01/2000, 2000.

Wool, R., 1995. In: The Science and Engineering of Polymer Composite Degradation. Degradable Polymers and Applications, Chapman and Hall, pp. 138-152. 